\title{
Spectrophotometric Determination of Bromhexine $\mathrm{HCl}$ in Pure and Pharmaceutical Forms
}

\author{
K. Susmitha, ${ }^{1}$ M. Thirumalachary, ${ }^{1}$ and G. Venkateshwarlu ${ }^{2}$ \\ ${ }^{1}$ Department of Chemistry, Jawaharlal Nehru Technology University, Hyderabad 500085, India \\ ${ }^{2}$ Department of Chemistry, Nizam College, Hyderabad 500001, India \\ Correspondence should be addressed to G. Venkateshwarlu; venkateshwarlugoud@yahoo.com
}

Received 8 June 2013; Accepted 3 July 2013

Academic Editors: E. Billiot, S. Göktürk, and D. Patra

Copyright (C) 2013 K. Susmitha et al. This is an open access article distributed under the Creative Commons Attribution License, which permits unrestricted use, distribution, and reproduction in any medium, provided the original work is properly cited.

Five spectrophotometric methods for determination of Bromhexine $\mathrm{HCl}$ have been developed, validated and applied for the assay of the drug in pharmaceuticals. Methods A, B and C are based on ion pair complexation of drug, in acidic buffers, with triphenylmethane dyes namely, Bromothymol blue (BTB), Bromophenol blue (BPB) and Bromocresol green (BCG). The complexes are extracted into chloroform and absorbance is measured around at $415 \mathrm{~nm}$ as function of concentration of the drug. The stoichiometry of the complex is found 1:1 in each case. Method D depends upon charge transfer complexation of neutralized drug with iodine which produces iodide ion whose absorbance at $366 \mathrm{~nm}$ is measured as function of concentration of the drug. This complex, too, has 1:1 composition as determined by Job's method. Method $\mathrm{E}$ is developed on the basis of oxidation of the drug with alkaline $\mathrm{KMnO}_{4}$ which generates green colored manganate ion with $\lambda_{\max } 610 \mathrm{~nm}$. As the intensity of green color increased with increasing time kinetics of the reaction is followed and calibration curves are constructed by using initial rate and fixed time methods. Excellent recovery studies with high accuracy and precision indicate that the methods can be successfully used in industries for the assay of drug in pure form and pharmaceuticals.

\section{Introduction}

Bromhexine $\mathrm{HCl}(\mathrm{BRH})$, chemically named 2-amino-3,5dibromo-N-cyclohexyl-N-methyl benzenemethanamine hydrochloride, is a mucolytic agent used in the treatment of respiratory disorders associated with viscid or excessive mucus [1, 2]. The drug is official in IP [3] and BP [4]. Because of its physiological importance, the drug has been quantified by exploiting its chemical $[5,6]$ and physical properties [7-25]. The different analytical methods used to quantify the drug as a single active pharmaceutical ingredient include flow injection analysis with ionselective electrodes [7], inductively coupled plasma mass spectrometry [8], electrokinetic chromatography [9], electrochemical oxidation at the glassy carbon electrode [10], liquid chromatography [11], liquid gas chromatography [12], GC with mass detection [13], and voltammetry [14]. The drug has also been quantified in its combined formulations using HPLC [15-18], direct and derivative UV spectrophotometry
[19-23]. These methods involve scarcely available costly equipment and tedious experimentation. Simple, accurate, and precise methods using spectrophotometry have also been developed based on the production of chromophore by the interaction of the drug with an analytical reagent, as chromogen [24-26]. Availability of vast number of analytical reagents to serve as chromogens always leaves a lot of scope for pharmaceutical analysis. Thorough survey of the literature showed that the quantification methods of our interest are not reported yet, and hence in the present communication we report five quantification methods, namely, A, B, C, D, and E, that have been developed and validated for quantification of bromhexine $\mathrm{HCl}$ both in pure and pharmaceutical forms.

\section{Experiment}

2.1. Instruments. The UV-Visible spectra of the samples were recorded on SHIMADZU 140 double beam, Thermo Nicolet 


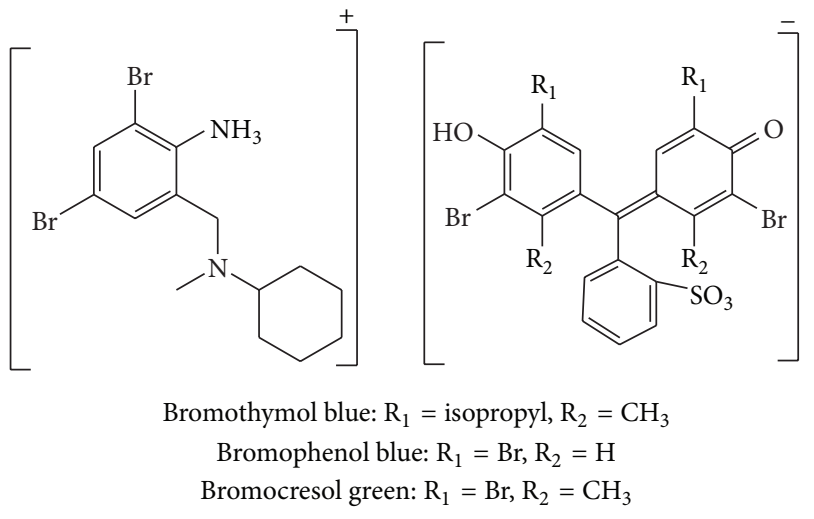

Scheme 1: Bromhexine HC1-dye complex.

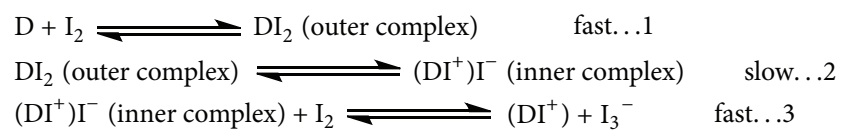

SCHEMe 2

1000 and ELICO 159 UV-Visible single beam spectrophotometers using quartz cells of $10 \mathrm{~mm}$ path length. An Elico model Li-120 $\mathrm{pH}$ meter was used for $\mathrm{pH}$ measurement.

2.2. Materials. HPLC grade chloroform, 1,2 Dichloroethane (DCE), Analytical grade (AR) $\mathrm{HCl}$, Sodium acetate, $\mathrm{KMnO}_{4}$, Sodium hydroxide and dyes viz., (a) BTB (b) BPB (c) BCG supplied by Sd Fine Chemicals, Mumbai, were used in the study. Iodine (BDH, Poole, UK) was twice sublimed and preserved in vacuum desiccator $\left(\mathrm{mp} 113.6-3^{\circ} \mathrm{C}\right)$. Iodine in 1,2-dichloroethane (DCE) was freshly prepared (daily) by dissolving $254 \mathrm{mg}$ solute in $50 \mathrm{~mL}$ of solvent $\left(4.0 \times 10^{-3} \mathrm{M}\right)$. The drug was procured from Aurobindo Pharmaceuticals, Hyderabad, as a gift sample.

2.3. Methods A, B, and C. The methods A, B, and $\mathrm{C}$ are based on the interaction of the drug with bromothymol blue (BTB), bromophenol blue (BPB), and bromocresol green (BCG), respectively, to form chloroform-extractable ion pair complexes (Scheme 1) which absorb around $415 \mathrm{~nm}$ (Figure 1). The absorbance of this band increases with increasing the concentration of the drug and formed a basis for the quantification of the drug. The dyestuffs were used as $0.025 \%$ solutions in doubly distilled water. Sodium acetate hydrochloric acid buffers of $\mathrm{pH} 2.8,2.5$, and 3.5 were prepared by mixing $50 \mathrm{~mL}$ of $1.0 \mathrm{M}$ sodium acetate solution with $49.50 \mathrm{~mL}, 50.50 \mathrm{~mL}$, and $46.25 \mathrm{~mL}$ of $1.0 \mathrm{M} \mathrm{HCl}$ solution, respectively, and diluted to $250 \mathrm{~mL}$ with doubly distilled water. The $\mathrm{pH}$ of each solution was adjusted to an appropriate value with the aid of a $\mathrm{pH}$ meter.

2.4. Method D Interaction of Iodine with Drug. The method depends upon the interaction of neutralized drug with iodine that generates iodide ion having an absorption band at $366 \mathrm{~nm}$ (Figure 2). The absorbance of this band increases

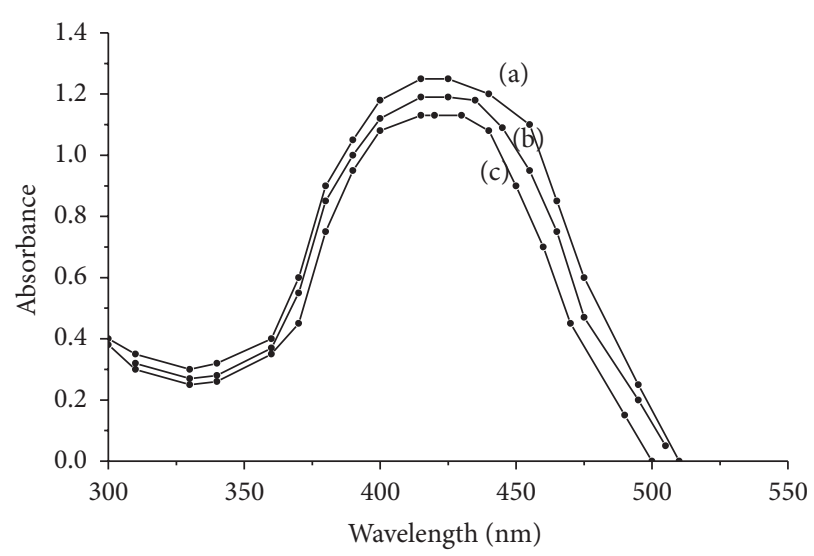

FIGURE 1: Absorption spectra of bromhexine hydrochloride-dye complex extracted into $10 \mathrm{~mL}$ chloroform: (a) drug $=10 \mu \mathrm{g} \mathrm{mL}^{-1}+$ $5 \mathrm{~mL}$ of $0.025 \% \mathrm{BTB}+5 \mathrm{~mL}$ of $\mathrm{pH} 2.8$ buffer, (b) drug $=9 \mu \mathrm{g} \mathrm{mL}^{-1}+$ $5 \mathrm{~mL}$ of $0.025 \% \mathrm{BPB}+5 \mathrm{~mL}$ of $\mathrm{pH} 2.5$ buffer, and (c) drug = $9.5 \mu \mathrm{g} \mathrm{mL}^{-1}+5 \mathrm{~mL}$ of $0.025 \% \mathrm{BCG}+5 \mathrm{~mL}$ of $\mathrm{pH} 3.5$ buffer.

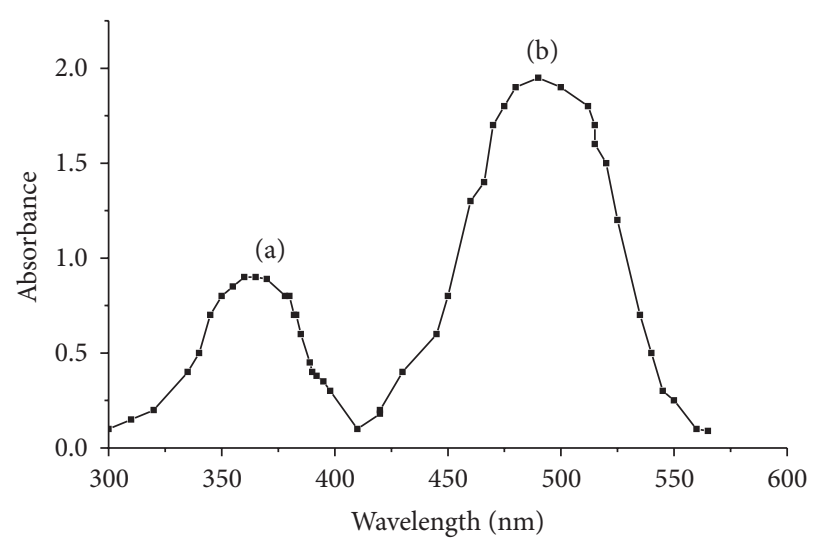

FIGURE 2: Absorption spectra of (a) reaction product of $12.5 \mu \mathrm{g} \mathrm{mL}^{-1}$ bromhexine hydrochloride with iodine in 1,2-dichloroethane and (b) iodine.

with increasing the concentration of the drug and formed a basis for the quantification of the drug. Mixing the solution of iodine prepared in DCE with BRH resulted in a change of violet color of iodine into light brown to pale yellow color, and as a consequence, absorption spectra exhibited a new band of $366 \mathrm{~nm}$. This is attributed due to $\mathrm{I}_{3}{ }^{-}$ion formed by the interaction of iodine with drug (Scheme 2).

2.5. Method E: Kinetic Method. The method depends on the oxidation of the drug with alkaline $\mathrm{KMnO}_{4}\left(1 \times 10^{-2} \mathrm{M}\right)$ to produce manganate ion which absorbs at $610 \mathrm{~nm}$ (Figure 3) and formed a basis for quantification of drug. A solution of $0.45 \mathrm{M} \mathrm{NaOH}$ is used to produce required alkalinity. Mixing the solutions of permanganate and the drug slowly developed green colour, and hence kinetics of the reaction was followed spectrophotometrically with a view to develop a method for the quantitative determination of the drug spectrophotometrically. The initial rate and fixed time methods are followed for the determination of $\mathrm{BRH}$. 
TABLE 1: Optical characteristics, precision, and accuracy data.

\begin{tabular}{|c|c|c|c|c|c|}
\hline Parameters & $\mathrm{BTB}(\mathrm{A})$ & $\mathrm{BPB}(\mathrm{B})$ & $\mathrm{BCG}(\mathrm{C})$ & $\mathrm{I}_{2}(\mathrm{D})$ & $\mathrm{KMnO}_{4}(\mathrm{E})$ \\
\hline$\lambda_{\max }(\mathrm{nm})$ & 412.00 & 414.00 & 415.00 & 366.00 & 610.00 \\
\hline Beer's law limit $\left(\mu \mathrm{g} \mathrm{mL}^{-1}\right)$ & $2.5-25$ & $2.5-25$ & $2.0-25$ & $5-50$ & $12.5-150$ \\
\hline Sandell's sensitivity $\left(\mu \mathrm{g} \mathrm{cm}^{-2}\right)$ & 0.03 & 0.05 & 0.01 & 0.02 & 0.35 \\
\hline Slope (specific absorptivity), $b$ & 0.03 & 0.02 & 0.01 & 0.06 & 0.05 \\
\hline Intercept $(a)$ & 0.16 & 0.05 & 0.06 & 0.01 & 0.03 \\
\hline Correlation coefficient $(r)$ & 1.00 & 1.00 & 1.00 & 1.00 & 1.00 \\
\hline $\begin{array}{l}\text { Standard deviation of intercepts } \\
(\% n=6)\end{array}$ & 0.02 & 0.01 & 0.01 & 0.06 & 0.01 \\
\hline Limit of detection, $\mu \mathrm{g} \mathrm{mL}^{-1}$ & 2.12 & 1.65 & 2.58 & 3.53 & 11.30 \\
\hline Limit of quantification, $\mu \mathrm{g} \mathrm{mL} \mathrm{L}^{-1}$ & 6.37 & 4.95 & 7.74 & 10.60 & 34.10 \\
\hline Regression equation & $\begin{array}{c}y=0.0311 \times \\
C+0.1598\end{array}$ & $\begin{array}{l}y=0.02 \times \\
C+0.047\end{array}$ & $\begin{array}{c}y=0.0115 \times \\
C+0.059\end{array}$ & $\begin{array}{c}y=0.056 \times \\
C+0.009\end{array}$ & $\begin{array}{c}y=0.0029 x \\
C+0.027\end{array}$ \\
\hline
\end{tabular}

$Y=a \times C+b$, where $C$ is the concentration in $\mu \mathrm{g} \mathrm{m}^{-1}$.

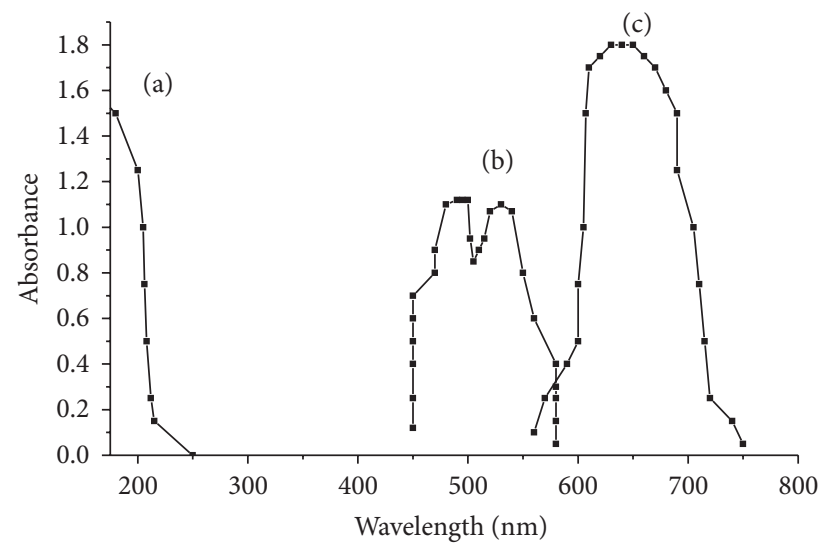

Figure 3: Absorption spectra of (a) drug (b) $\mathrm{KMnO}_{4}\left(1 \times 10^{-2} \mathrm{M}\right)$, and (c) reaction product of $15 \mu \mathrm{g} \mathrm{mL}^{-1}$ bromhexine hydrochloride with alkaline $\mathrm{KMnO}_{4}$.

2.6. Calibration Curves for Methods A, B, and C. Different aliquots of drug solution were transferred into $125 \mathrm{~mL}$ separating funnel. To this $5 \mathrm{~mL}$ of buffer, $5 \mathrm{~mL}$ of dye was added, and total volume was made up to $20 \mathrm{~mL}$ with water. $10 \mathrm{~mL}$ of chloroform was added, and the contents were shaken for $5 \mathrm{~min}$. The two layers were allowed to separate for $5 \mathrm{~min}$. The organic layer was separated, and absorbance of yellowcolored solution which is stable at least for $3 \mathrm{hrs}$ is measured at $415 \mathrm{~nm}$ against blank similarly prepared. The same procedure of analysis is followed either for assay of pure drug or for dosage form. The calibration graphs are linear for the drug analysed using these dyes (Figure 4).

2.7. Calibration Curve for Method D. Into separate $10 \mathrm{~mL}$ volumetric flasks different aliquots of $\mathrm{BRH}$ solution was transferred followed by the addition of $1 \mathrm{~mL}$ of iodine solution. The volume was completed using the same solvent and the absorbance was measured against reagent blank at $366 \mathrm{~nm}$.

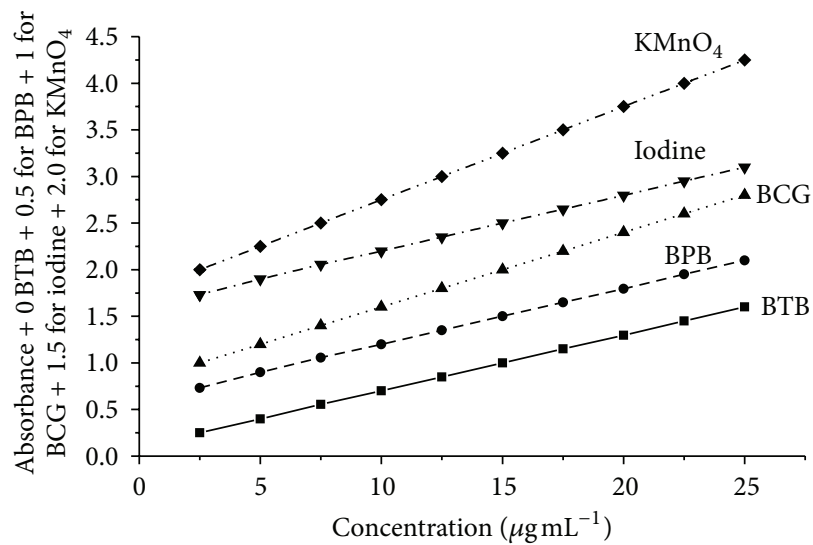

FIGURE 4: Calibration curves.

\subsection{Calibration Curve for Method E}

2.8.1. Initial Rate Method. Aliquots of 1 to $8 \mathrm{~mL}$ of bromhexine $\mathrm{HCl}$ solution containing $2.5 \mathrm{mg} \mathrm{mL}^{-1}$ of drug were pipetted into a series of $10 \mathrm{~mL}$ standard flasks. To each flask, $1.0 \mathrm{~mL}$ of $0.45 \mathrm{M} \mathrm{NaOH}$ and $1 \mathrm{~mL}$ of $1 \times 10^{-2} \mathrm{M}$ potassium permanganate were added successively and then diluted with distilled water at $25 \pm 1^{\circ} \mathrm{C}$. The contents of each flask were mixed well, and the increase in absorbance as a function of time was measured at $610 \mathrm{~nm}$. The initial rate of the reaction $(v)$ at different concentrations was evaluated by measuring the slope of the tangent to the absorbance-time plot. The calibration graphs were obtained by plotting the initial rate of reaction $(v)$ versus concentration of bromhexine $\mathrm{HCl}$.

2.8.2. Fixed Time Method. A fixed time of 20 min was selected for the fixed time method. At this time the absorbance of reaction mixture measured against a reagent blank prepared similarly. The calibration curve was obtained by plotting the absorbance against the initial concentration of bromhexine $\mathrm{HCl}$. Table 1 summarizes the limits of Beer's law, Limit of Detection (LOD), Limit of quantification (LOQ), molar 
TABLE 2: Application of proposed methods for the determination of $\mathrm{BRH}$ in pure form.

\begin{tabular}{|c|c|c|c|c|c|}
\hline $\mathrm{BRH}$ & BTB (A) & $\mathrm{BPB}(\mathrm{B})$ & $\mathrm{BCG}(\mathrm{C})$ & $\mathrm{I}_{2}(\mathrm{D})$ & $\mathrm{KMnO}_{4}(\mathrm{E})$ \\
\hline \multirow{5}{*}{ Taken $\left(\mu \mathrm{g} \mathrm{mL}^{-1}\right)$} & 3.00 & 3.00 & 3.00 & 5.00 & 20.00 \\
\hline & 6.00 & 6.00 & 6.00 & 10.00 & 25.00 \\
\hline & 9.00 & 9.00 & 9.00 & 15.00 & 30.00 \\
\hline & 12.00 & 12.00 & 12.00 & 20.00 & 35.00 \\
\hline & 15.00 & 15.00 & 15.00 & 25.00 & 40.00 \\
\hline \multirow{5}{*}{ Found $\left(\mu \mathrm{g} \mathrm{mL}^{-1}\right)$} & 3.01 & 3.04 & 3.10 & 4.99 & 20.02 \\
\hline & 6.05 & 6.03 & 6.09 & 10.05 & 24.95 \\
\hline & 8.99 & 9.08 & 9.10 & 15.02 & 30.05 \\
\hline & 11.98 & 12.06 & 12.08 & 19.95 & 35.06 \\
\hline & 15.10 & 14.96 & 14.98 & 24.96 & 39.96 \\
\hline \multirow{5}{*}{ Recovery (\%) } & 99.67 & 98.68 & 96.77 & 100.20 & 99.90 \\
\hline & 99.17 & 99.50 & 98.52 & 99.50 & 100.20 \\
\hline & 100.11 & 99.12 & 98.90 & 99.87 & 99.83 \\
\hline & 100.17 & 99.50 & 99.34 & 100.25 & 99.83 \\
\hline & 99.34 & 100.27 & 100.13 & 100.16 & 100.10 \\
\hline Mean & 99.69 & 99.42 & 98.73 & 100.00 & 99.97 \\
\hline SD & 1.50 & 1.80 & 1.25 & 1.60 & 1.25 \\
\hline Reference method [14] & $99.77 \pm 0.48$ & $99.77 \pm 0.48$ & $99.77 \pm 0.48$ & $99.77 \pm 0.48$ & $99.77 \pm 0.48$ \\
\hline$t$-test $(1.10)^{*}$ & 0.11 & 0.42 & 1.73 & 0.31 & 0.33 \\
\hline$F$-test $(2.61)^{*}$ & 2.25 & 3.24 & 1.56 & 2.56 & 1.56 \\
\hline
\end{tabular}

Each result is the average of five separate determinations. ${ }^{*}$ Values in paranthesis are thetabulated $t$ and $F$ values, at $P=0.05$ [27].

absorptivity, regression equation, correlation coefficients and relative standard deviations.

\subsection{Assay of Drug in Pharmaceuticals}

2.9.1. Procedure for the Assay of Pure Drug. Five different solutions of pure drug in the range of calibration curve were selected, and the recovery experiments were performed. The recoveries and their relative standard deviation are tabulated in (Table 2).

2.9.2. Procedure for the Assay of Dosage Forms. Ten tablets of bromhexine $8 \mathrm{mg}$ are powdered and dissolved in doubly distilled water and stirred thoroughly and then filtered through a Whatman number 42 filter paper. This solution was transferred into $100 \mathrm{~mL}$ standard volumetric flask and diluted with doubly distilled water as required. Different solutions of drug in the range of calibration curve were chosen, and the assay was estimated using the calibration curve and the results of the recovery studies are tabulated in (Table 3).

\section{Results and Discussion}

3.1. Methods $A, B$, and $C$. BRH forms ion-pair complexes in acidic buffer with dyestuffs viz., BTB, BPB and BCG. These complexes are quantitatively extracted into chloroform. The ion-pair complexes with BTB, BPB and BCG absorbed maximally at $415 \mathrm{~nm}$ (Figure 1). The reagent blank under similar conditions showed no absorption. BRH contains aromatic amine group which is protonated in acidic medium, while sulphonic acid group is present in BTB: that is the only group undergoing dissociation in the $\mathrm{PH}$ range $1-5$. BPB and BCG are examples of sulphonepthalein type of dye. The colour of such dyes is due to the opening of lactoid ring and subsequent formation of quinoid group. It is supposed that the two tautomers are present in equilibrium but due to strong acidic nature of the sulphonic acid group, the quinoid body must predominate. Finally the protonated BRH forms ion-pairs with the dyestuffs which are quantitatively extracted into chloroform.

3.2. Stoichiometry. In order to establish molar ratio between $\mathrm{BRH}$ and dyestuffs used, Job's method of continuous variation (Figure 5) has been applied [28]. In this method, solutions of drug and dyestuff with identical molar concentrations $\left(8 \times 10^{-5} \mathrm{M}\right)$ were mixed in varying volume ratios in such a way that the total volume of each mixture was the same. The absorbance of each solution was measured and plotted against the mole fraction of the drug, [drug]/[drug] + [dyestuff].

This measurement showed that $1: 1$ complex was formed. Job's method of stoichiometry is also applied for iodine with $\mathrm{BRH}$ which indicated that the charge-transfer complex formed is of $1: 1$ composition.

The stoichiometric ratio between bromhexine $\mathrm{HCl}$ and potassium permanganate was evaluated by limiting logarithmic method [29]. In this method two sets of experiments were performed. In the first set the concentration of $\mathrm{BRH}$ was varied keeping a constant concentration of $\mathrm{KMnO}_{4}$, while in the second set the concentration of BRH was kept constant and the $\mathrm{KMnO}_{4}$ concentration was varied. Log absorbance versus $\log [\mathrm{BRH}]$ or $\left[\mathrm{KMnO}_{4}\right]$ was plotted to 
TABLE 3: Application of proposed methods for the determination of BRH in pharmaceutical preparation.

\begin{tabular}{|c|c|c|c|c|c|}
\hline $\mathrm{BRH}$ & BTB (A) & $\mathrm{BPB}(\mathrm{B})$ & $\mathrm{BCG}(\mathrm{C})$ & $\mathrm{I}_{2}(\mathrm{D})$ & $\mathrm{KMnO}_{4}(\mathrm{E})$ \\
\hline \multirow{4}{*}{ Taken $\left(\mu \mathrm{g} \mathrm{mL}^{-1}\right)$} & 5.00 & 5.00 & 5.00 & 10.00 & 20.00 \\
\hline & 7.00 & 7.00 & 7.00 & 20.00 & 30.00 \\
\hline & 9.00 & 9.00 & 9.00 & 30.00 & 40.00 \\
\hline & 11.00 & 11.00 & 11.00 & 40.00 & 50.00 \\
\hline \multirow{4}{*}{ Found $\left(\mu \mathrm{g} \mathrm{mL}^{-1}\right)$} & 4.95 & 5.04 & 4.98 & 9.96 & 20.06 \\
\hline & 6.94 & 6.97 & 7.06 & 19.94 & 29.95 \\
\hline & 9.05 & 8.97 & 9.05 & 29.96 & 40.03 \\
\hline & 10.94 & 11.07 & 11.08 & 40.02 & 50.09 \\
\hline \multirow{4}{*}{ Recovery (\%) } & 101.01 & 99.21 & 100.40 & 100.40 & 99.70 \\
\hline & 100.86 & 100.43 & 99.15 & 100.30 & 100.17 \\
\hline & 99.45 & 100.33 & 99.45 & 100.13 & 99.93 \\
\hline & 100.55 & 99.37 & 99.28 & 99.95 & 99.82 \\
\hline Mean & 100.47 & 99.83 & 99.57 & 100.20 & 99.90 \\
\hline $\mathrm{SD}$ & 1.12 & 1.55 & 2.20 & 0.97 & 1.70 \\
\hline Reference method [14] & $99.77 \pm 0.48$ & $99.77 \pm 0.48$ & $99.77 \pm 0.48$ & $99.77 \pm 0.48$ & $99.77 \pm 0.48$ \\
\hline$t$-test $(1.10)^{*}$ & 1.28 & 0.08 & 0.19 & 0.88 & 0.16 \\
\hline$F$-test $(2.61)^{*}$ & 1.25 & 2.40 & 4.84 & 0.94 & 2.89 \\
\hline
\end{tabular}

Each result is the average of four separate determinations. ${ }^{*}$ Values in paranthesis are the tabulated $t$ and $F$ values, at $P=0.05$ [27].

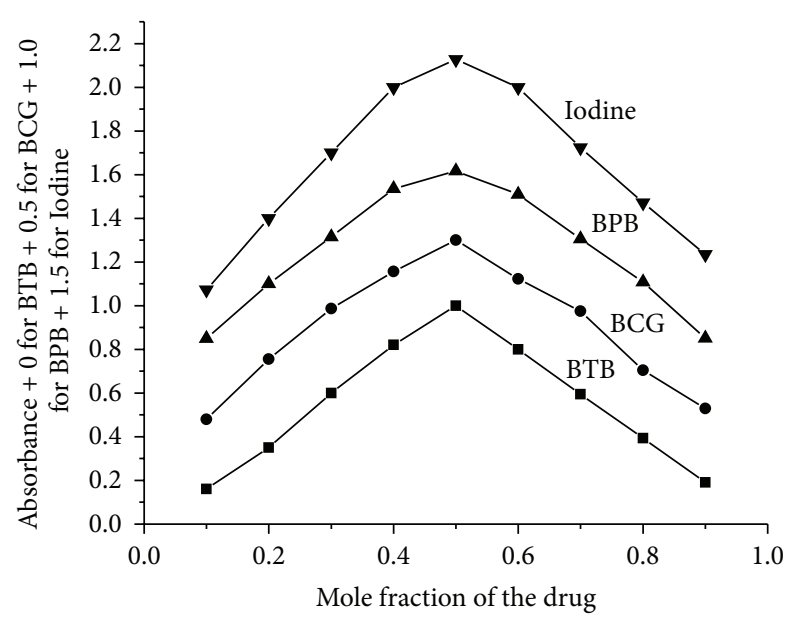

FIGURE 5: Jobs plots.

evaluate the slopes of the respective lines. From evaluation of slopes molar combining ratio is $5: 2$ between bromhexine $\mathrm{HCl}$ and potassium permanganate. The literature survey reveals that bromhexine $\mathrm{HCl}$ undergoes oxidation and gives rise to 2-amino-3, 5-dibromobenzaldehyde and $\mathrm{N}$-methyl cyclohexanamine [14] (Figure 6).

3.3. Formation Constants. The formation constants for method A, B and C are estimated from Job's plot by the following method described by Likussar and Boltz [30] and Momoki et al. [31]. The method involves drawing the tangents at the origin of Job's plot from both sides, and the absorbance at intersection point is taken for $100 \%$ complexation. The absorbance at peak height of Job's plot is taken for $(100-$ $x) \%$, where $x$ is the $\%$ degree of dissociation of the complex.
The instability constant, $K^{\prime}=C x /(100-x)$, is calculated, where $C$ is the concentration of drug used for Job's method. The reciprocal of $K^{\prime}$ is the required stability constant $K$.

3.4. Formation Constant for Method D. Formation constant $(K)$ has been evaluated by using Benesi-Hildebrand equation [32]:

$$
\frac{\left[A_{0}\right]}{d}=\frac{I}{K\left[D_{0}\right] \epsilon}+\frac{1}{\epsilon}
$$

where $d$ is absorbance, $\epsilon$ is molar absorptivity, and $A_{0}$ and $D_{0}$ are initial concentrations of acceptor $\left[\mathrm{I}_{2}\right]$ and donor [drug], respectively. A plot of $\left[A_{0}\right] / d$ versus $1 /\left[D_{0}\right]$ yields a straight line whose slope and intercept give the value of $K$.

3.5. Optimization of the Factors Affecting the Absorbance. The factors effecting the absorbance of ion-pair complexes like $\mathrm{pH}$ and volume of the dye, in methods $\mathrm{A}, \mathrm{B}$, and $\mathrm{C}$, have been optimized. $1.8 \mathrm{~mL}$ of BTB and buffer of $\mathrm{pH} 2.8,1.6 \mathrm{~mL}$ of $\mathrm{BPB}$ and buffer of $\mathrm{pH} 2.5$, and $2.0 \mathrm{~mL}$ of $\mathrm{BCG}$ and buffer of $\mathrm{pH} 3.5$ are found to be optimal for methods A, B, and C, respectively. However $5 \mathrm{~mL}$ of each dye is used, at optimal $\mathrm{pH}$, in the study to ensure complete extraction of the drug. Similarly the $1 \mathrm{~mL}$ of iodine for method $\mathrm{D}$ and $1 \mathrm{~mL}$ of $\mathrm{KMnO}_{4}, 1 \mathrm{~mL}$ of $0.45 \mathrm{NaOH}$ for method $\mathrm{E}$ are found to be optimal and hence are used in the study.

3.6. Validation of the Proposed Methods. The proposed methods have been validated in terms of guidelines proposed by ICH [33], namely, selectivity, specificity, accuracy, precision, limits of calibration curve, LOD, LOQ, robustness, ruggedness, and regression equation. Student's $t$-test and variance $F$-test have been performed in comparison with a reference 


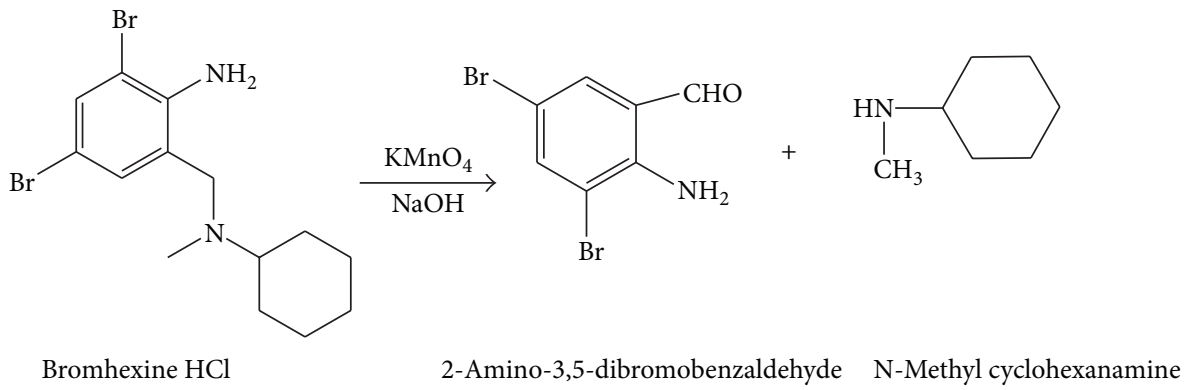

Figure 6: Oxidation of bromhexine $\mathrm{HCl}$ with alkaline $\mathrm{KMnO}_{4}$.

method. To test the reproducibility of the proposed methods, five replicate determinations of $15.0 \mu \mathrm{gmL}$ of $\mathrm{BRH}$ were made. The coefficient of variation was found to be less than $1.2 \%$ for all the procedures.

The proposed methods have been successfully applied to the determination of $\mathrm{BRH}$ in pharmaceutical preparations. The results obtained and shown in Table 1 were compared to those obtained by a reference method [14] by means of $t$ test at 95\% confidence level. In all cases, the average results obtained by proposed methods and reference method were statistically identical, as the difference between the average values had no significance at $95 \%$ confidence level.

\section{Conclusions}

The proposed spectrophotometric methods present selective and simple, specific, and inexpensive analytical procedures for determination of $\mathrm{BRH}$, in pure or in tablet dosage forms without interference from common excipients. Moreover, the developed methods are time saving and do not require elaborate treatments associated with chromatographic methods. These attributes make them suitable for routine analysis in quality control laboratories.

\section{Acknowledgments}

The authors are grateful to the Head, Department of Chemistry, and Principal, Nizam College, for providing facilities. The support rendered by Department of Chemistry, Jawaharlal Nehru Technology University, is duly acknowledged.

\section{References}

[1] L. Parvez, M. Vaidya, A. Sakhardande, S. Subburaj, and T. G. Rajagopalan, "Evaluation of antitussive agents in man," Pulmonary Pharmacology, vol. 9, no. 5-6, pp. 299-308, 1996.

[2] D. M. Cobbin, F. M. Elliott, and A. S. Rebuck, "The mucolytic agent bromhexine (bisolvon) in chronic lung disease. A doubleblind crossover trial," Australian and New Zealand Journal of Medicine, vol. 1, no. 2, pp. 137-140, 1971.

[3] Indian Pharmacopoeia 1996 and Addendum 2000 (Government of India, Ministry of Health and Family welfare. Controller of publications. New Delhi, India).

[4] British Pharmacopoeia, vol. 2, HMSO, London, UK, 1996.
[5] S. S. Zarapker, R. V. Rele, and V. J. Doshi, "Simple spectrophotometric methods for estimation of bromhexine hydrochloride," Indian Drugs, vol. 26, no. 1, pp. 38-41, 1988.

[6] M. I. R. M. Santoro, M. M. Dos Santos, and J. F. Magalhaes, "Spectrophotometric determination of bromhexine hydrochloride in pharmaceutical preparations," Journal of the Association of Official Analytical Chemists, vol. 67, no. 3, pp. 532-534, 1984.

[7] N. T. Abdel-Ghani, Y. M. Issa, and H. M. Ahmed, "Potentiometric flow injection analysis of bromhexine hydrochloride and its pharmaceutical preparation using conventional and coated wire ion-selective electrodes," Scientia Pharmaceutica, vol. 74, no. 3, pp. 121-135, 2006.

[8] B. P. Jensen, B. Gammelgaard, S. H. Hansen, and J. V. Andersen, "HPLC-ICP-MS compared with radiochemical detection for metabolite profiling of $3 \mathrm{H}$-bromohexine in rat urine and faeces," Journal of Analytical Atomic Spectrometry, vol. 20, no. 3, pp. 204-209, 2005.

[9] H. Okamoto, T. Nakajima, Y. Ito, T. Aketo, K. Shimada, and S. Yamato, "Simultaneous determination of ingredients in a cold medicine by cyclodextrin-modified microemulsion electrokinetic chromatography," Journal of Pharmaceutical and Biomedical Analysis, vol. 37, no. 3, pp. 517-528, 2005.

[10] M. Pospísilová, M. Polasek, and V. Jokl, "Determination of ambroxol or bromhexine in pharmaceuticals by capillary isotachophoresis," Journal of Pharmaceutical and Biomedical Analysis, vol. 24, no. 3, pp. 421-428, 2001.

[11] E. V. Rao, G. R. Rao, S. Raghuveer, and P. Khadgapathi, "Gas-liquid chromatographic and ion-pair high-performance liquid chromatographic determination of pseudoephedrine hydrochloride and bromhexine hydrochloride in pharmaceuticals," Analyst, vol. 112, no. 6, pp. 871-874, 1987.

[12] O.-W. Lau and Y.-M. Cheung, "Simultaneous determination of some active ingredients in cough - cold syrups by gas-liquid chromatography," Analyst, vol. 115, no. 10, pp. 1349-1353, 1990.

[13] C. E. Uboh, J. A. Rudy, L. R. Soma et al., "Characterization of bromhexine and ambroxol in equine urine: effect of furosemide on identification and confirmation," Journal of Pharmaceutical and Biomedical Analysis, vol. 9, no. 1, pp. 33-39, 1991.

[14] M. Turchán, P. Jara-Ulloa, S. Bollo, L. J. Nuñez-Vergara, J. A. Squella, and A. Álvarez-Lueje, "Voltammetric behaviour of bromhexine and its determination in pharmaceuticals," Talanta, vol. 73, no. 5, pp. 913-919, 2007.

[15] J.-P. Rauha, H. Salomies, and M. Aalto, "Simultaneous determination of bromhexine hydrochloride and methyl and propyl p-hydroxybenzoate and determination of dextromethorphan hydrobromide in cough-cold syrup by high-performance liquid chromatography," Journal of Pharmaceutical and Biomedical Analysis, vol. 15, no. 2, pp. 287-293, 1996. 
[16] M. Vasudevan, S. Ravisankar, M. George, and J. Ravi, "Simultaneous estimation of terbutaline, bromhexine and guaiphenesin in soft gelatin capsules by HPLC method," Indian Drugs, vol. 37, no. 10, pp. 489-492, 2000.

[17] H. N. Dave, R. C. Mashru, and A. K. Patel, "Thin layer chromatodraphy method for the determination of ternary mixture containing salbutamol sulphate, bromhexine hydrochloride and Etofylline," Journal of Pharmaceutical Sciences and Research, vol. 2, no. 3, pp. 143-148, 2010.

[18] A. El-Gindy, S. Emara, and H. Shaaban, "Development and validation of chemometrics-assisted spectrophotometric and liquid chromatographic methods for the simultaneous determination of two multicomponent mixtures containing bronchodilator drugs," Journal of Pharmaceutical and Biomedical Analysis, vol. 43, no. 3, pp. 973-982, 2007.

[19] V. Gupta, M. Verma, U. Misra, and R. K. Nema, "Simultaneous spectrophotoetric estimation of bromhexine hydrochloride and pseudoephedrine hydrochloride in tablet dosages," Asian Journal of Chemistry, vol. 21, no. 2, pp. 1633-1635, 2009.

[20] A. K. Gupta and S. G. Kaskhedikar, "Derivative spectrophotometric estimation of amoxycillin and bromhexine hydrochloride in tablets," Asian Journal of Chemistry, vol. 15, no. 2, pp. 977-980, 2003.

[21] S. K. Panda, A. K. Sharma, and L. K. Sahu, "Simultaneous analysis of phenylpropanolamine, chlorpheniramine and bromhexine in syrups by derivative spectrophotometry," Indian Journal of Pharmaceutical Sciences, vol. 64, no. 6, pp. 540-544, 2002.

[22] S. Gangwal and P. Trivedi, "Simultaneous determination of terbutaline sulphate, bromhexine hydrochloride and guaiphenesin in three-component tablet formulation by UV spectrophotometry," Indian Journal of Pharmaceutical Sciences, vol. 61, no. 1-6, pp. 128-130, 1999.

[23] X. Song, X. Wang, and D. Ze, "Determination of aminophylline and bromhexine hydrochloride in Dingchuanzhike tablets by UV spectrophotometry," Zhongguo Yaoke Daxue Xuebao, vol. 30, no. 2, pp. 100-102, 1999.

[24] S. V. Murali Mohan Rao, I. Nageswara Rao, T. Rama Subba Reddy, and C. S. P. Sastry, "Assay of bromhexine hydrochloride in pharmaceutical formulations by extraction spectrophotometry," Indian Journal of Chemical Technology, vol. 12, no. 2, pp. 170-174, 2005.

[25] S. V. Murali Mohan Rao, U. Viplava Prasad, I. Nageswara Rao, and M. Satya Babu, "Sensitive spectrophotometric methods for the determination of bromhexine hydrochloride," Acta Ciencia Indica, Chemistry, vol. 30, no. 2, pp. 105-108, 2004.

[26] S. Kanna Babu, P. A. V. Ganapathi, N. V. S. N. Raju, and G. MadhuKumar, "Spectrophotometric estimation of bromhexine hydrochloride in pharmaceutical preparations," Eastern Pharmacist, vol. 42, no. 493, pp. 135-136, 1999.

[27] J. C. Miller and J. N. Miller, Statistics and Chemometrics for Analytical Chemistry, Harlow, England, 2005.

[28] P. Job, Analytica Chimica Acta 16 ,1936, in Advanced Physicochemical Experiments, Oliner and Boyd, Edinburgh, UK, 2nd edition.

[29] J. Rose, Advanced Physicochemical Experiments, Pitman, London, UK, 1964.

[30] W. Likussar and D. F. Boltz, "Theory of continuous variations plots and a new method for spectrophotometric determination of extraction and formation constants," Analytical Chemistry, vol. 43 , no. 10, pp. 1265-1272, 1971.
[31] K. Momoki, J. Sekino, H. Sato, and N. Yamaguchi, "Theory of curved molar ratio plots and a new linear plotting method," Analytical Chemistry, vol. 41, no. 10, pp. 1286-1299, 1969.

[32] H. A. Benesi and J. H. Hildebrand, "A spectrophotometric investigation of the interaction of iodine with aromatic hydrocarbons," Journal of the American Chemical Society, vol. 71, no. 8, pp. 2703-2707, 1949.

[33] International Conference on Harmonization (ICH) of Technical Requirement for the Registration of Pharmaceuticals for Human use, Validation of analytical procedures: definitions and Terminology Genera, 1996. 

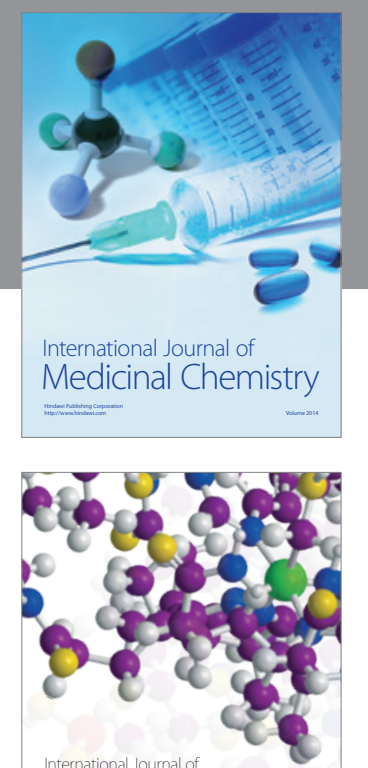

\section{Carbohydrate} Chemistry

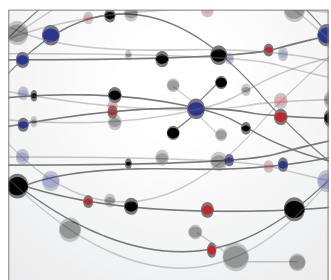

The Scientific World Journal
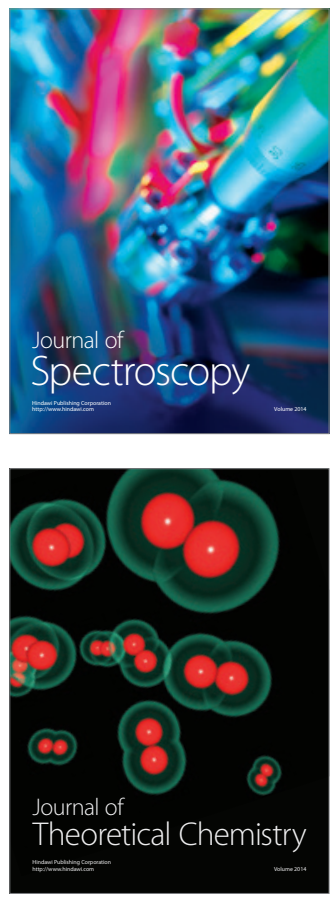
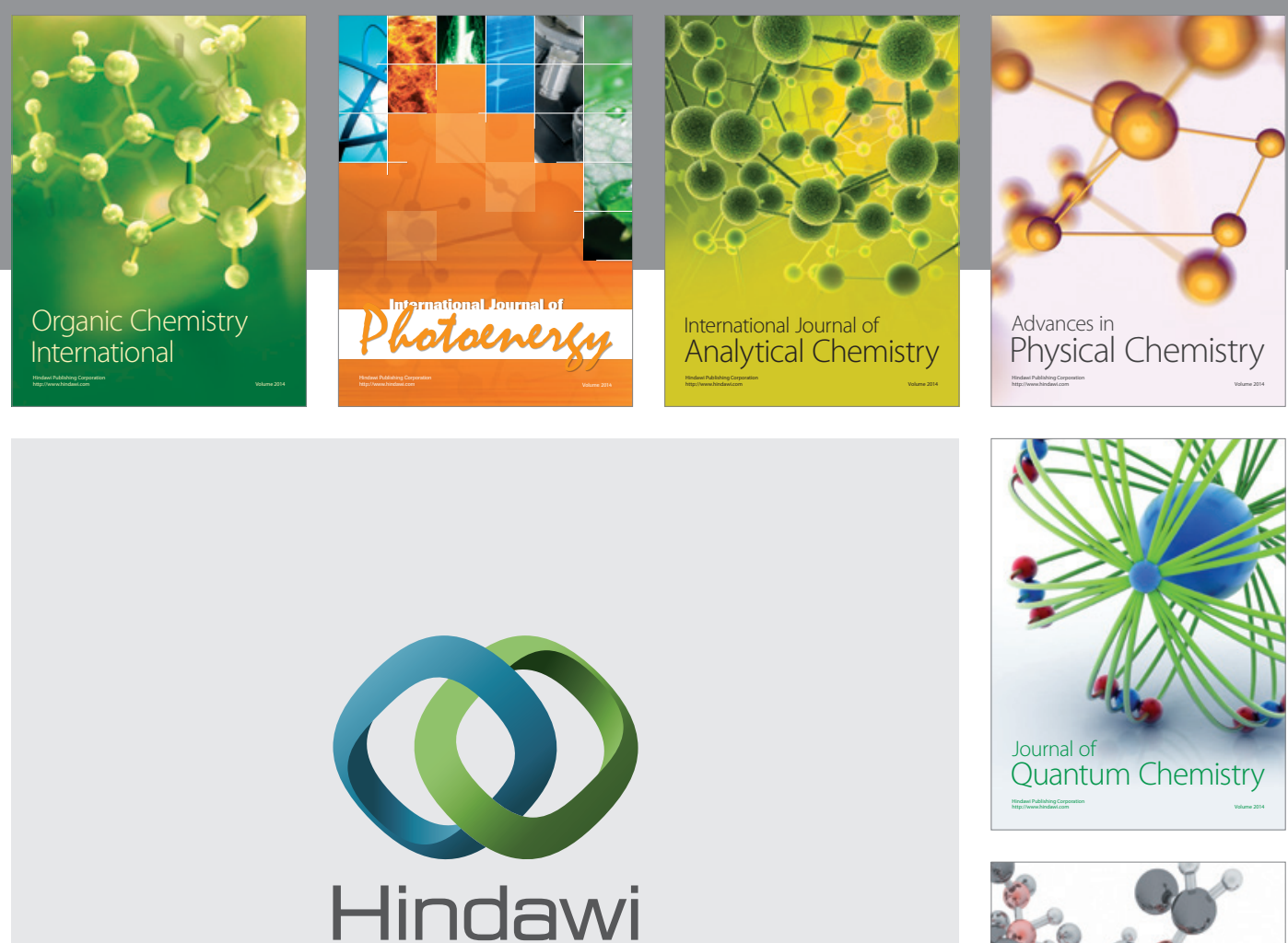

Submit your manuscripts at

http://www.hindawi.com

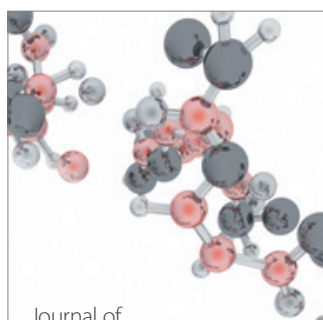

Analytical Methods

in Chemistry

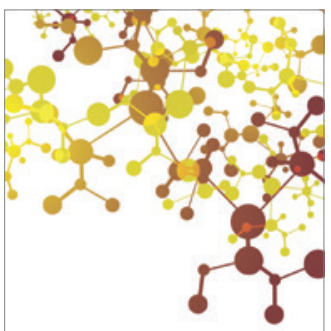

Journal of

Applied Chemistry

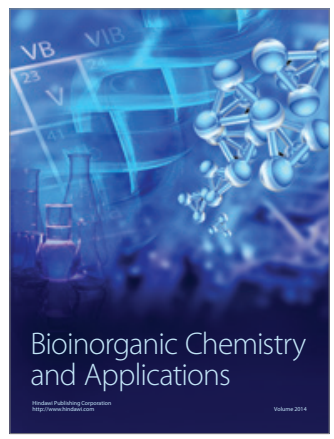

Inorganic Chemistry
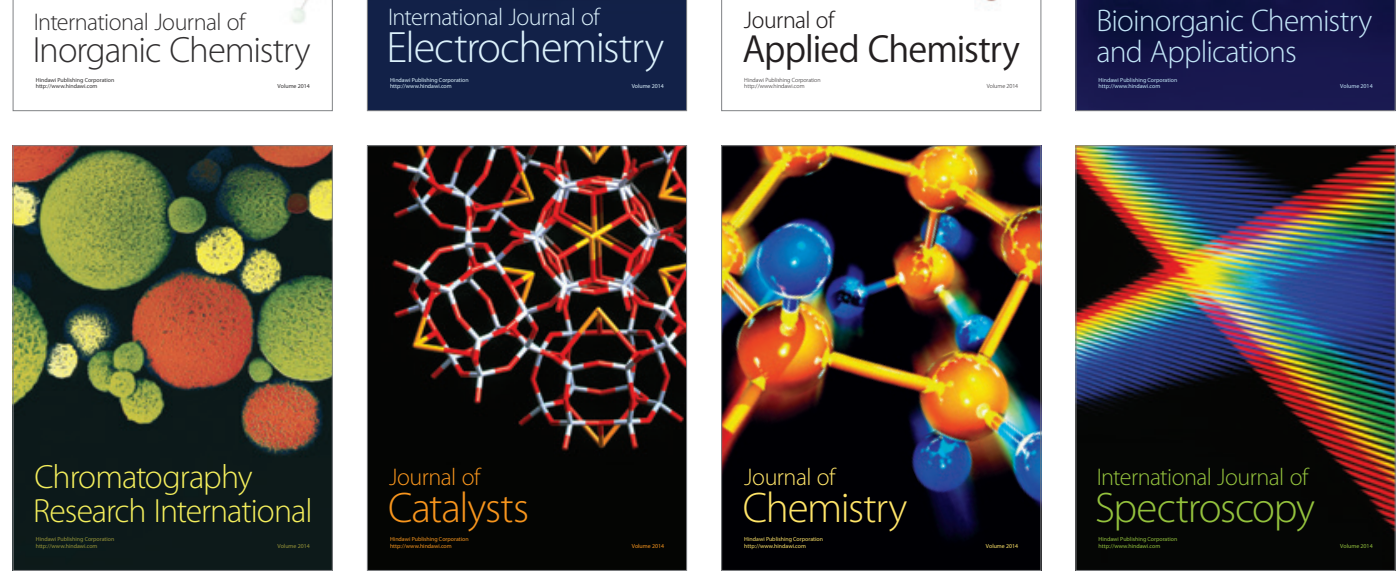